\title{
The Parameter Reduction of Fuzzy Soft Sets Based on Soft Fuzzy Rough Sets
}

\author{
Zhiming Zhang \\ College of Mathematics and Computer Science, Hebei University, Baoding, Hebei 071002, China \\ Correspondence should be addressed to Zhiming Zhang; zhimingzhang@ymail.com
}

Received 28 September 2012; Revised 21 April 2013; Accepted 8 May 2013

Academic Editor: Martine de Cock

Copyright (c) 2013 Zhiming Zhang. This is an open access article distributed under the Creative Commons Attribution License, which permits unrestricted use, distribution, and reproduction in any medium, provided the original work is properly cited.

\begin{abstract}
Fuzzy set theory, rough set theory, and soft set theory are three effective mathematical tools for dealing with uncertainties and have many wide applications both in theory and practise. Meng et al. (2011) introduced the notion of soft fuzzy rough sets by combining fuzzy sets, rough sets, and soft sets all together. The aim of this paper is to study the parameter reduction of fuzzy soft sets based on soft fuzzy rough approximation operators. We propose some concepts and conditions for two fuzzy soft sets to generate the same lower soft fuzzy rough approximation operators and the same upper soft fuzzy rough approximation operators. The concept of reduct of a fuzzy soft set is introduced and the procedure to find a reduct for a fuzzy soft set is given. Furthermore, the concept of exclusion of a fuzzy soft set is introduced and the procedure to find an exclusion for a fuzzy soft set is given.
\end{abstract}

\section{Introduction}

Soft set theory [1], firstly proposed by Molodtsov, is a general mathematical tool for dealing with uncertainty. Since its introduction, soft set theory has been successfully applied in many fields such as functions smoothness, game theory, riemann integration, and theory of measurement [1]. In recent year, soft set theory has received much attention [219].

It is worth noting that all of above works are based on the classical soft set theory. A lot of extensions of soft sets to uncertain environments have been proposed recently, such as fuzzy soft sets [20], generalised fuzzy soft sets [21], intervalvalued fuzzy soft sets [22], vague soft sets [23], intuitionistic fuzzy sets [24-26], and interval-valued intuitionistic fuzzy soft sets [27]. More importantly, some approaches to these extended soft sets-based decision makings were also developed [21, 28-32].

Rough set theory was originally introduced by Pawlak [33] to deal with vagueness and granularity in information systems. The equivalence relation is the key in Pawlak's rough set model. However, the equivalence relation is too restrictive for many practical applications. Therefore, some extensions of Pawlak's rough sets have been developed by replacing the equivalence relations by some more general concepts. For example, by using arbitrary binary relaions, fuzzy relations, and intuitionistic fuzzy relations to granulate the universe of discourse, the concepts of variable precision rough sets, fuzzy rough sets, and intuitionistic fuzzy rough sets have been presented, respectively. But all these rough sets have their inherent difficulties, which are caused by the inadequacy of the parametrization tool. For example, in variable precision fuzzy rough sets, a large number of experiments are required to define the distribution function, which is expensive in some practical problems. In fuzzy rough sets and intuitionistic fuzzy rough sets, defining a membership function and a nonmembership function is not an easy task. In classical rough sets, the equivalence relation is a very stringent condition that limits the applications of rough sets in some practical problems. The mentioned difficulties associated with these rough sets are because of lack of parametrization tools. Different from these existing rough set extensions, by employing fuzzy soft sets to granulate the universe of discourse, Meng et al. [34] constructed a more general model called the soft fuzzy rough set, which is free from the inadequacy of the parametrization tools of those rough sets and therefore can overcome the above difficulties. Sun and Ma [35] also proposed a new concept of soft fuzzy rough set by combining the fuzzy soft set with the pseudo fuzzy soft set. In this paper, we study the parameter reduction 
of fuzzy soft sets based on soft fuzzy rough sets proposed by Meng et al. [34]. Our work is substantially different from Sun and Ma's work [35]. First, our work is based on Ma et al.s soft fuzzy rough sets, which are different from Sun and Ma's soft fuzzy rough sets. Second, our work mainly studies the parameter reduction of fuzzy soft sets based on soft fuzzy rough sets, while Sun and Ma's work [35] focused on the application of soft fuzzy rough sets in decision making.

As for a fuzzy soft set, if we omit a parameter from the set of parameters, then the resulting new fuzzy soft sets and the original one can generate the same lower soft fuzzy rough approximation operators and the same upper soft fuzzy rough approximation operators. This phenomenon tells us that there may exist redundancy in a fuzzy soft set. As a consequence, how to get rid of the redundancy from a fuzzy soft set is an important and interesting research issue. To address this issue, we in the current paper introduce two concepts of reduct and exclusion. Furthermore, a procedure to find the reduct or exclusion of a set of parameters is given. For a particular fuzzy soft set, our technique can obtain the corresponding "smallest" fuzzy soft set that produces the same lower soft fuzzy rough approximation operators and the same upper soft fuzzy rough approximation operators. Hence, our method can reduce the redundant information in a fuzzy soft set. In addition, it should also be noted that in soft fuzzy rough set models, different fuzzy soft sets may generate the same lower soft fuzzy rough approximation operators and the same upper soft fuzzy rough approximation operators. Therefore, it is necessary to find the conditions under which two fuzzy soft sets generate the same lower soft fuzzy rough approximation operators and the same upper soft fuzzy rough approximation operators. In this paper, we extend Zhu and Wang's work [36] and propose some concepts and conditions for two fuzzy soft sets to generate the same lower soft fuzzy rough approximation operators and the same upper soft fuzzy rough approximation operators.

This paper is organized as follows. Section 2 introduces some fundamental concepts. In Section 3, we propose one of the core concepts in this paper, reduct, to reduce a set of parameters to its simplest form while not changing the lower soft fuzzy rough approximation operator $\underline{A p r}_{\subseteq}^{\prime}$ and the upper soft fuzzy rough approximation operator $\overline{\mathrm{Apr}}_{\widetilde{S}}^{\prime}$. Still, through this concept, we get a sufficient condition for two fuzzy soft sets to generate the same lower soft fuzzy rough approximation operator $\mathrm{Apr}_{\Im}^{\prime}$ and the same upper soft fuzzy rough approximation operator $\overline{\mathrm{Apr}}_{\Im}^{\prime}$. In Section 4, we investigate similar issues to those in Section 3 for the the lower soft fuzzy rough approximation operator $\underline{A p r}_{\widetilde{S}}$ and the upper soft fuzzy rough approximation operator $\overline{\mathrm{Apr}}_{\widetilde{\subseteq}}$. This paper concludes in Section 5 with remarks for future works.

\section{Preliminaries}

In this section, we shall briefly recall some basic notions of soft sets and rough sets.
2.1. Soft Sets and Fuzzy Soft Sets. Throughout this paper, let $U$ be an initial universe of objects and $E_{U}(E$, for short) the set of parameters in relation to objects in $U$. Parameters are often attributes, characteristics, or properties of objects. Let $\mathscr{P}(U)$ denote the power set of $U$ and $A \subseteq E$. Molodtsov [1] defined the soft set in the following way.

Definition 1 (see [1]). A pair $(F, A)$ is called a soft set over $U$, where $F$ is a mapping given by

$$
F: A \longrightarrow \mathscr{P}(U) \text {. }
$$

Such a mapping reflects the innate character of the concept of a soft set; that is, a soft set is a mapping from parameters to $\mathscr{P}(U)$. This shows that a soft set over $U$ is a parameterized family of subsets of the universe $U$. For $\varepsilon \in A$, $F(\varepsilon)$ is regarded as the set of $\varepsilon$-approximate elements of the soft set $(F, A)$.

As an illustration, let us consider the following example originally introduced by Molodtsov [1].

Example 2 (a house purchase problem). Suppose that the universe $U=\left\{x_{1}, x_{2}, x_{3}, x_{4}, x_{5}, x_{6}\right\}$ is the set of six houses under consideration and $A$ is the set of parameters that Mr. X is interested in buying a house. Assume that $A=$ $\left\{\varepsilon_{1}, \varepsilon_{2}, \varepsilon_{3}, \varepsilon_{4}, \varepsilon_{5}, \varepsilon_{6}\right\}$, where $\varepsilon_{i}(i=1,2,3,4,5,6)$ stands for the parameters in a word of "expensive," "beautiful," "wooden," "in the green surroundings," "convenient traffic," and "modern style," respectively. That means, out of available houses in $U, \mathrm{Mr}$. X is to select that house which qualifies with all (or with maximum number of) parameters of the set $A$. In this case, to define a soft set means to point out expensive houses, beautiful houses, and so on. The soft set $(F, A)$ describes the "attractiveness of the houses" which Mr. X (say) is going to buy.

Suppose that

$$
\begin{array}{cc}
F\left(\varepsilon_{1}\right)=\left\{x_{2}, x_{6}\right\}, & F\left(\varepsilon_{2}\right)=\left\{x_{1}, x_{4}, x_{5}\right\}, \\
F\left(\varepsilon_{3}\right)=\left\{x_{3}, x_{4}, x_{5}, x_{6}\right\}, & F\left(\varepsilon_{4}\right)=\left\{x_{1}, x_{2}, x_{3}, x_{5}\right\}, \\
F\left(\varepsilon_{5}\right)=\left\{x_{2}\right\}, & F\left(\varepsilon_{6}\right)=\left\{x_{1}, x_{3}\right\} .
\end{array}
$$

The soft set $(F, A)$ is a parameterized family $\left\{F\left(\varepsilon_{i}\right), i=\right.$ $1,2,3,4,5,6\}$ of subsets of the set $U$ and gives us a collection of approximate descriptions of an object. Consider the mapping $F$ which is "houses (.)" where $\operatorname{dot}(\cdot)$ is to be filled up by a parameter $\varepsilon \in A$. For instance, $F\left(\varepsilon_{1}\right)$ means "houses (expensive)" whose functional value is the set $\{h \in$ $U, h$ is an expensive house $\}=\left\{x_{2}, x_{6}\right\}$. Thus, we can view the soft set $(F, A)$ as a collection of approximations as below:

$$
(F, A)=\left\{\begin{array}{l}
\text { expensive houses }=\left\{x_{2}, x_{6}\right\}, \\
\text { beautiful houses }=\left\{x_{1}, x_{4}, x_{5}\right\}, \\
\text { wooden houses }=\left\{x_{3}, x_{4}, x_{5}, x_{6}\right\}, \\
\text { houses in the green surroundings } \\
\quad=\left\{x_{1}, x_{2}, x_{3}, x_{5}\right\}, \\
\text { convenient traffic houses }=\left\{x_{2}\right\}, \\
\text { modern style houses }=\left\{x_{1}, x_{3}\right\}
\end{array}\right\} .
$$

In order to store a soft set in a computer, we could represent a soft set in the form of a 0 -1 two-dimensional table. 
TABLE 1: Tabular representation of $(F, A)$.

\begin{tabular}{ccccccc}
\hline$U$ & $\varepsilon_{1}$ & $\varepsilon_{2}$ & $\varepsilon_{3}$ & $\varepsilon_{4}$ & $\varepsilon_{5}$ & $\varepsilon_{6}$ \\
\hline$x_{1}$ & 0 & 1 & 0 & 1 & 0 & 1 \\
$x_{2}$ & 1 & 0 & 0 & 1 & 1 & 0 \\
$x_{3}$ & 0 & 0 & 1 & 1 & 0 & 1 \\
$x_{4}$ & 0 & 1 & 1 & 0 & 0 & 0 \\
$x_{5}$ & 0 & 1 & 1 & 1 & 0 & 0 \\
$x_{6}$ & 1 & 0 & 1 & 0 & 0 & 0 \\
\hline
\end{tabular}

TABLE 2: Tabular representation of $(F, A)$.

\begin{tabular}{ccccccc}
\hline$U$ & $\varepsilon_{1}$ & $\varepsilon_{2}$ & $\varepsilon_{3}$ & $\varepsilon_{4}$ & $\varepsilon_{5}$ & $\varepsilon_{6}$ \\
\hline$x_{1}$ & 0.6 & 0.6 & 0.1 & 0.6 & 0.5 & 0.5 \\
$x_{2}$ & 0.8 & 0.8 & 0.4 & 0.8 & 0.1 & 0.4 \\
$x_{3}$ & 0.4 & 0.2 & 0.4 & 0.3 & 0.3 & 0.4 \\
$x_{4}$ & 0.6 & 0.1 & 0.6 & 0.5 & 0.5 & 0.6 \\
$x_{5}$ & 0.5 & 0.5 & 0.1 & 0.5 & 0.3 & 0.3 \\
$x_{6}$ & 0.7 & 0.6 & 0.7 & 0.9 & 0.9 & 0.9 \\
\hline
\end{tabular}

Table 1 is the tabular representation of the soft set $(F, A)$. If $x_{i} \in F\left(\varepsilon_{j}\right)$, then $x_{i j}=1$; otherwise $x_{i j}=0$, where $x_{i j}$ are the entries in Table 1 .

By Definition 1, a soft set is a parameterized family of subsets of the universal set. In other words, a soft set is a mapping from a set of parameters to the power set of an initial universe set. In the real world, the difficulty is that the objects in the universal set may not precisely satisfy the problem's parameters. Maji et al. [20] initiated the study on hybrid structures involving both fuzzy sets and soft sets. They introduced in [20] the notion of fuzzy soft sets, which can be seen as a fuzzy generalization of (classical) soft sets. The concept of fuzzy soft sets partially resolves this difficulty.

Definition 3 (see [20]). Let $\mathscr{F}(U)$ be the set of all fuzzy subsets of $U$. Let $E$ be a set of parameters and $A \subseteq E$. A pair $(F, A)$ is called a fuzzy soft set over $U$, where $F$ is a mapping given by $F: A \rightarrow \mathscr{F}(U)$.

A fuzzy soft set $(F, A)$ is a parameterized family of fuzzy subsets of $U$; thus, $(F, A)$ can be reexpressed as follows: $(F, A)=\{F(\varepsilon) \mid \varepsilon \in A\}$. A fuzzy soft set is actually a special case of a soft set because it is still a mapping from parameters to a universe. The difference between a soft set and a fuzzy soft set is that in a fuzzy soft set, the universe to be considered is the set of fuzzy subsets of $U$. Generally speaking, for any parameter $\varepsilon \in A, F(\varepsilon)$ is a fuzzy subset of $U$ and it is called fuzzy value set of parameter $\varepsilon . F(\varepsilon)$ can be written as $F(\varepsilon)=\left\{\left\langle x, \mu_{F(\varepsilon)}(x)\right\rangle \mid x \in U\right\}$. Let us denote $\mu_{F(\varepsilon)}(x)$ by the membership degree that object $x \in U$ holds parameter $\varepsilon \in A$.

Definition 4. A fuzzy soft set $(F, A)$ over $U$ is called a full fuzzy soft set if $\bigcup_{a \in A} F(a)=U$.

Example 5 (Example 2 Continued). Let $U$ be a set of six houses and $A$ a set of parameters given by Example 2. Now suppose that all the available information of the six houses with respect to the five parameters can be formulated as a fuzzy soft set $(F, A)$ describing "attractiveness of houses" that $\mathrm{Mr}$. X is going to buy. According to the data collected, the fuzzy soft set $(F, A)$ can be viewed as the collection of the following fuzzy approximations:

$$
\begin{aligned}
& \begin{aligned}
F\left(\varepsilon_{1}\right)= & \text { expensive houses }=\left\{\left\langle x_{1}, 0.6\right\rangle,\left\langle x_{2}, 0.8\right\rangle,\left\langle x_{3}, 0.4\right\rangle,\right. \\
& \left.\left\langle x_{4}, 0.6\right\rangle,\left\langle x_{5}, 0.5\right\rangle,\left\langle x_{6}, 0.7\right\rangle\right\}, \\
F\left(\varepsilon_{2}\right) & =\text { beautiful houses }=\left\{\left\langle x_{1}, 0.6\right\rangle,\left\langle x_{2}, 0.8\right\rangle,\left\langle x_{3}, 0.2\right\rangle,\left\langle x_{4},\right.\right. \\
& \left.0.1\rangle,\left\langle x_{5}, 0.5\right\rangle,\left\langle x_{6}, 0.6\right\rangle\right\},
\end{aligned} \\
& \begin{aligned}
F\left(\varepsilon_{3}\right) & =\text { wooden houses }=\left\{\left\langle x_{1}, 0.1\right\rangle,\left\langle x_{2}, 0.4\right\rangle,\left\langle x_{3}, 0.4\right\rangle,\left\langle x_{4},\right.\right. \\
& \left.0.6\rangle,\left\langle x_{5}, 0.1\right\rangle,\left\langle x_{6}, 0.7\right\rangle\right\}, \\
F\left(\varepsilon_{4}\right) & =\text { in the green surroundings houses }=\left\{\left\langle x_{1}, 0.6\right\rangle,\left\langle x_{2},\right.\right. \\
& \left.0.8\rangle,\left\langle x_{3}, 0.3\right\rangle,\left\langle x_{4}, 0.5\right\rangle,\left\langle x_{5}, 0.5\right\rangle,\left\langle x_{6}, 0.9\right\rangle\right\}, \\
F\left(\varepsilon_{5}\right)= & \text { convenient traffic houses }=\left\{\left\langle x_{1}, 0.5\right\rangle,\left\langle x_{2}, 0.1\right\rangle,\left\langle x_{3},\right.\right. \\
& \left.0.3\rangle,\left\langle x_{4}, 0.5\right\rangle,\left\langle x_{5}, 0.3\right\rangle,\left\langle x_{6}, 0.9\right\rangle\right\}, \\
F\left(\varepsilon_{6}\right)= & \text { modern style houses }=\left\{\left\langle x_{1}, 0.5\right\rangle,\left\langle x_{2}, 0.4\right\rangle,\left\langle x_{3}, 0.4\right\rangle,\right. \\
& \left.\left\langle x_{4}, 0.6\right\rangle,\left\langle x_{5}, 0.3\right\rangle,\left\langle x_{6}, 0.9\right\rangle\right\} .
\end{aligned}
\end{aligned}
$$

Table 2 is the tabular representation of the fuzzy soft set $(F, A)$.

Definition 6 (see [20]). For two fuzzy soft sets $(F, A)$ and $(G, B)$ over $U$, we say that $(F, A)$ is a fuzzy soft subset of $(G, B)$ if and only if $A \subseteq B$ and $\forall \varepsilon \in A, F(\varepsilon) \subseteq G(\varepsilon)$. We denote this relationship by $(F, A) \subseteq(G, B)$. $(F, A)$ is said to be a fuzzy soft superset of $(G, B)$, if $(G, B)$ is a fuzzy soft subset of $(F, A)$. We denote it by $(F, A) \supseteq(G, B)$. If $(F, A)$ is a fuzzy soft subset of $(G, B)$ and $(G, B)$ is a fuzzy soft subset of $(F, A)$, then $(F, A)$ and $(G, B)$ are said to be fuzzy soft equal, which can be denoted by $(F, A)=(G, B)$.

It is easy to see that $(F, A)=(G, B)$ if and only if $A=B$ and $F(\varepsilon)=G(\varepsilon)$ for any $\varepsilon \in A$.

2.2. Pawlak's Rough Sets and Rough Fuzzy Sets. In this subsection we recall basic definitions of classical rough sets and rough fuzzy sets.

Let $U$ denote a finite and nonempty set called the universe. Suppose $R \subseteq U \times U$ is an equivalence relation on $U$; that is, $R$ is reflexive, symmetrical, and transitive. The equivalence relation $R$ partitions the set $U$ into disjoint subsets. It is a quotient set of the universe and is denoted by $U / R$. Elements in the same equivalence class are said to be indistinguishable. Equivalence classes of $R$ are called elementary sets. Every union of elementary sets is called a definable set [33]. The empty set is considered to be a definable set; thus, all the definable sets form a Boolean algebra. $(U, R)$ is called a Pawlak approximation space. Given an arbitrary set $X \subseteq U$, one can characterize $X$ by a pair of lower and upper approximations. The lower approximation $\underline{R}(X)$ is the greatest definable set contained in $X$, and the upper approximation $\bar{R}(X)$ is the 
smallest definable set containing $X$. They can be computed by two equivalent formulae:

$$
\begin{gathered}
\underline{R}(X)=\left\{x \mid[x]_{R} \subseteq X\right\}, \\
\bar{R}(X)=\left\{x \mid[x]_{R} \cap X \neq \emptyset\right\}, \\
\underline{R}(X)=\cup\left\{[x]_{R} \mid[x]_{R} \subseteq X\right\}, \\
\bar{R}(X)=\cup\left\{[x]_{R} \mid[x]_{R} \cap X \neq \emptyset\right\},
\end{gathered}
$$

where $[x]_{R}=\{y \mid x R y\}$ is the equivalence class containing $x$.

Dubois and Prade [37] first generalized the concept of rough sets to the fuzzy environment [38] and initiated the concepts of rough fuzzy sets and fuzzy rough sets. Next, we introduce the concept of rough fuzzy sets proposed by Dubois and Prade [37].

Let $(U, R)$ be a Pawlak approximation space. For a fuzzy set $\mu \in \mathscr{F}(U)$, the lower and upper rough approximations of $\mu$ with respect to $(U, R)$ are denoted by $\underline{R}(\mu)$ and $\bar{R}(\mu)$, respectively, which are fuzzy sets in $U$ defined by

$$
\begin{aligned}
& \underline{R}(\mu)(x)=\wedge\left\{\mu(y): y \in[x]_{R}\right\}, \\
& \bar{R}(\mu)(x)=\vee\left\{\mu(y): y \in[x]_{R}\right\},
\end{aligned}
$$

for all $x \in U$. The operators $\underline{R}$ and $\bar{R}$ are called the lower and upper rough approximation operators on fuzzy sets. If $\underline{R}(\mu)=$ $\bar{R}(\mu)$, the fuzzy set $\mu$ is said to be definable; otherwise, $\mu$ is called a rough fuzzy set.

2.3. Soft Fuzzy Rough Sets. Motivated by Dubois's and Prade's original idea about rough fuzzy sets, Feng et al. [9] considered the lower and upper approximations of a soft set in a Pawlak's approximation space, which gave rise to the notion of rough soft sets. Next, in [10], a soft set instead of an equivalence relation was used to granulate the universe of discourse. The result was a deviation of Pawlak's approximation space called a soft approximation space, in which soft rough approximations and soft rough sets were introduced accordingly. Furthermore, Feng et al. [9] considered lower and upper soft rough approximations of fuzzy sets in a soft approximation space and obtained a new hybrid model called soft rough fuzzy sets, which can be seen as an extension of Dubois's and Prade's rough fuzzy sets. Recently, Meng et al. [34] used a fuzzy soft set to granulate the universe of discourse and obtained two new hybrid models called soft fuzzy rough sets, which can be seen as an extension of soft rough fuzzy sets. In the following, we recall two pairs of soft fuzzy rough approximation operators as follows.

Definition 7 (see [34]). Let $\mathfrak{S}=(F, A)$ be a fuzzy soft set over $U$ and $\mathrm{SF}=(U, \mathfrak{S})$ be a soft fuzzy approximation space. For a fuzzy set $\mu \in \mathscr{F}(U)$, the lower soft fuzzy rough approximation
$\operatorname{Apr}_{\Phi}^{\prime}(\mu)$ and upper soft fuzzy rough approximation $\overline{\operatorname{Apr}}_{\widetilde{S}}^{\prime}(\mu)$ of $\mu$ with respect to SF are fuzzy sets in $U$ given by

$$
\begin{aligned}
& \overline{\operatorname{Apr}}_{\Im}(\mu)(x) \\
& \quad=\bigvee_{\varepsilon \in A}\left(F(\varepsilon)(x) \wedge\left(\bigwedge_{y \in U}((1-F(\varepsilon)(y)) \vee \mu(y))\right)\right), \\
& \overline{\operatorname{Apr}}_{\Im}^{\prime}(\mu)(x) \\
& \quad=\bigwedge_{\varepsilon \in A}\left((1-F(\varepsilon)(x)) \vee\left(\bigvee_{y \in U}(F(\varepsilon)(y) \wedge \mu(y))\right)\right),
\end{aligned}
$$

for all $x \in U$.

Definition 8 (see [34]). Let $\mathbb{S}=(F, A)$ be a fuzzy soft set over $U$. The pair $\mathrm{SF}=(U, \mathbb{S})$ is called a soft fuzzy approximation space. For a fuzzy set $\mu \in \mathscr{F}(U)$, the lower and upper soft fuzzy rough approximations of $\mu$ with respect to SF are denoted by $\operatorname{Apr}_{\Im}(\mu)$ and $\overline{\operatorname{Apr}}_{\Im}(\mu)$, respectively, which are fuzzy sets in $\bar{U}$ given by

$$
\begin{aligned}
& \operatorname{Apr}_{\mathbb{S}}(\mu)(x) \\
& =\bigwedge_{\varepsilon \in A}((1-F(\varepsilon)(x)) \\
& \left.\quad \vee\left(\bigwedge_{y \in U}((1-F(\varepsilon)(y)) \vee \mu(y))\right)\right), \\
& \overline{\operatorname{Apr}}_{\mathbb{S}}(\mu)(x) \\
& =\bigwedge_{\varepsilon \in A}\left(F(\varepsilon)(x) \wedge\left(\bigvee_{y \in U}(F(\varepsilon)(y) \wedge \mu(y))\right)\right),
\end{aligned}
$$

for all $x \in U$. The operators $\underline{\mathrm{Apr}}_{\mathbb{S}}$ and $\overline{\mathrm{Apr}}_{\mathfrak{S}}$ are called the lower and upper soft fuzzy rough approximation operators on fuzzy sets. If $\underline{\operatorname{Apr}}_{\Phi}(\mu)=\overline{\operatorname{Apr}}_{\Im}(\mu), \mu$ is said to be soft fuzzy definable; otherwise $\mu$ is called a soft fuzzy rough set.

\section{Reducts of the Lower Soft Fuzzy Rough Approximation Operator $\mathrm{Apr}^{\prime}$ and Upper Soft Fuzzy Rough Approximation Operator $\overline{\mathrm{Apr}}_{\mathbb{S}}^{\prime}$}

It is worth noting that two different fuzzy soft sets may generate the same lower soft fuzzy rough approximation operator Apr $_{\subseteq}^{\prime}$ and upper soft fuzzy rough approximation operator $\overline{\mathrm{Apr}}_{\mathfrak{\Phi}}$; therefore, it is necessary to obtain the conditions under which two different fuzzy soft sets generate the same lower soft fuzzy rough approximation operator $\mathrm{Apr}_{\Im}^{\prime}$ and upper soft fuzzy rough approximation operator $\overline{\mathrm{Apr}}_{\mathfrak{S}}^{\prime}$. In addition, there 
TABLE 3: Tabular representation of $(G, B)$.

\begin{tabular}{lccccc}
\hline$U$ & $\varepsilon_{1}$ & $\varepsilon_{2}$ & $\varepsilon_{3}$ & $\varepsilon_{4}$ & $\varepsilon_{5}$ \\
\hline$x_{1}$ & 0.6 & 0.6 & 0.1 & 0.6 & 0.5 \\
$x_{2}$ & 0.8 & 0.8 & 0.4 & 0.8 & 0.1 \\
$x_{3}$ & 0.4 & 0.2 & 0.4 & 0.3 & 0.3 \\
$x_{4}$ & 0.6 & 0.1 & 0.6 & 0.5 & 0.5 \\
$x_{5}$ & 0.5 & 0.5 & 0.1 & 0.5 & 0.3 \\
$x_{6}$ & 0.7 & 0.6 & 0.7 & 0.9 & 0.9 \\
\hline
\end{tabular}

TABLE 4: Tabular representation of $(H, C)$.

\begin{tabular}{lcccc}
\hline$U$ & $\varepsilon_{1}$ & $\varepsilon_{2}$ & $\varepsilon_{3}$ & $\varepsilon_{5}$ \\
\hline$x_{1}$ & 0.6 & 0.6 & 0.1 & 0.5 \\
$x_{2}$ & 0.8 & 0.8 & 0.4 & 0.1 \\
$x_{3}$ & 0.4 & 0.2 & 0.4 & 0.3 \\
$x_{4}$ & 0.6 & 0.1 & 0.6 & 0.5 \\
$x_{5}$ & 0.5 & 0.5 & 0.1 & 0.3 \\
$x_{6}$ & 0.7 & 0.6 & 0.7 & 0.9 \\
\hline
\end{tabular}

TABle 5: Tabular representation of $(J, D)$.

\begin{tabular}{llll}
\hline$U$ & $\varepsilon_{2}$ & $\varepsilon_{3}$ & $\varepsilon_{5}$ \\
\hline$x_{1}$ & 0.6 & 0.1 & 0.5 \\
$x_{2}$ & 0.8 & 0.4 & 0.1 \\
$x_{3}$ & 0.2 & 0.4 & 0.3 \\
$x_{4}$ & 0.1 & 0.6 & 0.5 \\
$x_{5}$ & 0.5 & 0.1 & 0.3 \\
$x_{6}$ & 0.6 & 0.7 & 0.9 \\
\hline
\end{tabular}

may also exist redundancy in a fuzzy soft set; that is, if we remove a parameter from a set of parameters, the remaining fuzzy soft set and the original fuzzy soft set can generate the same lower soft fuzzy rough approximation operator Apr $^{\prime} \subseteq$ and upper soft fuzzy rough approximation operator $\overline{\operatorname{Apr}}_{\Im}^{\prime}$. Therefore, deletion of redundancy from a fuzzy soft set is an important topic. In this section, we are devoted to solving these problems.

Example 9 (different fuzzy soft sets generate the same $\operatorname{Apr}_{\Phi}^{\prime}$ and $\left.\overline{\operatorname{Apr}}_{\Im}^{\prime}\right)$. Let $(F, A)$ be a fuzzy soft set over $U$ shown in Table 2. Let $(G, B),(H, C)$, and $(J, D)$ be three fuzzy soft sets over $U$ shown in Tables 3, 4, and 5, where $B=$ $\left\{\varepsilon_{1}, \varepsilon_{2}, \varepsilon_{3}, \varepsilon_{4}, \varepsilon_{5}\right\}=$ expensive; beautiful; wooden; in the green surroundings; convenient traffic $\}, C=\left\{\varepsilon_{1}, \varepsilon_{2}, \varepsilon_{3}, \varepsilon_{5}\right\}=$ \{expensive; beautiful; wooden; convenient traffic\}, and $D=$ $\left\{\varepsilon_{2}, \varepsilon_{3}, \varepsilon_{5}\right\}=\{$ beautiful; wooden; convenient traffic $\}$.

Through computing, we find that $(F, A),(G, B),(H, C)$ and $(J, D)$ generate the same lower soft fuzzy rough approximation operator $\underline{A p r}_{\subseteq}^{\prime}$ and the same upper soft fuzzy rough approximation operator $\overline{\mathrm{Apr}}_{\mathfrak{⿷}}^{\prime}$. Therefore, we want to investigate the conditions under which two different fuzzy soft sets generate the same lower soft fuzzy rough approximation operator $\mathrm{Apr}_{\subseteq}^{\prime}$ and the same upper soft fuzzy rough approximation operator $\overline{\mathrm{Apr}}_{\mathbb{E}}^{\prime}$.

Definition 10. Let $(F, A)$ be a fuzzy soft set over a universe $U$ and $a \in A$. If $F(a)$ is a union of some fuzzy sets in $\{F(\varepsilon) \mid \varepsilon \in$ $A-\{a\}\}$, then $a$ is called a reducible element of $A$; otherwise, $a$ is called an irreducible element of $A$.

Proposition 11. Let $(F, A)$ be a fuzzy soft set over $U$. Then $\varepsilon$ is a reducible element of $A$ if and only if, for any $x \in U$, there exists a parameter $\varepsilon_{x} \in A-\{\varepsilon\}$ such that $F(\varepsilon)(x)=F\left(\varepsilon_{x}\right)(x)$.

Proof. According to Definition 10, we have $\varepsilon$ is a reducible element of $A$ :

$$
\begin{aligned}
\Leftrightarrow & F(\varepsilon)=\bigcup_{\varepsilon \in A-\{a\}} F(\varepsilon), \\
\Leftrightarrow & F(\varepsilon)(x)=\bigvee_{\varepsilon \in A-\{a\}} F(\varepsilon)(x), \text { for all } x \in U, \\
\Leftrightarrow & \text { there exists a parameter } \varepsilon_{x} \in A-\{\varepsilon\} \text { such that } \\
& F(\varepsilon)(x)=F\left(\varepsilon_{x}\right)(x) \text {, for all } x \in U .
\end{aligned}
$$

Example 12. In Table 2, we can easily see that $F\left(\varepsilon_{1}\right)=F\left(\varepsilon_{2}\right) \cup$ $F\left(\varepsilon_{3}\right)$. Therefore, by Definition $10, \varepsilon_{1}$ is a reducible element of A.

Definition 13. Let $(F, A)$ be a fuzzy soft set over a universe $U$. If every element of $A$ is an irreducible element, then we call $A$ irreducible; otherwise, $A$ is reducible.

Theorem 14. Let $(F, A)$ be a full fuzzy soft set over $U$. If $a$ is a reducible element of $A$, then $\{F(\varepsilon) \mid \varepsilon \in A-\{a\}\}$ is still a full fuzzy soft set over $U$.

Proof. It directly follows from Definitions 4 and 10.

Theorem 15. Let $(F, A)$ be a fuzzy soft set over a universe $U$, let $a \in A$, let $a$ be a reducible element of $A$, and let $b \in A-\{a\}$; then, $b$ is a reducible element of $A$ if and only if it is a reducible element of $A-\{a\}$.

Proof. " $\Rightarrow$ " If $b$ is a reducible element of $A$, then $F(b)$ can be expressed as a union of some fuzzy subsets in $\{F(\varepsilon) \mid \varepsilon \in$ $A-\{b\}\}$, denoted by $F\left(\varepsilon_{i_{1}}\right), F\left(\varepsilon_{i_{2}}\right), \ldots, F\left(\varepsilon_{i_{n}}\right)$. It is clear that $F\left(\varepsilon_{i_{k}}\right) \subset F(b)$ for $k=1,2, \ldots, n$. If all fuzzy sets among $F\left(\varepsilon_{i_{1}}\right), F\left(\varepsilon_{i_{2}}\right), \ldots, F\left(\varepsilon_{i_{n}}\right)$ are not equal to $F(a)$, then $F\left(\varepsilon_{i_{1}}\right)$, $F\left(\varepsilon_{i_{2}}\right), \ldots, F\left(\varepsilon_{i_{n}}\right) \subseteq\{F(\varepsilon) \mid \varepsilon \in A-\{a\}\}-\{F(b)\}$. Thus, $b$ is a reducible element of $A-\{a\}$. If some one among $F\left(\varepsilon_{i_{1}}\right), F\left(\varepsilon_{i_{2}}\right), \ldots, F\left(\varepsilon_{i_{n}}\right)$ is equal to $F(a)$, without loss of generality, let $F\left(\varepsilon_{i_{1}}\right)=F(a)$. Since $a$ is a reducible element of $A$, there exist fuzzy sets $F\left(\varepsilon_{j_{1}}\right), F\left(\varepsilon_{j_{2}}\right), \ldots, F\left(\varepsilon_{j_{m}}\right) \in\{F(\varepsilon) \mid$ $\varepsilon \in A-\{a\}\}$, such that $F\left(\varepsilon_{i_{1}}\right)=F(a)=\bigcup_{k=1}^{m} F\left(\varepsilon_{j_{k}}\right)$. Therefore, $F(b)=\bigcup_{k=1}^{n} F\left(\varepsilon_{i_{k}}\right)=\left(\bigcup_{k=1}^{m} F\left(\varepsilon_{j_{k}}\right)\right) \cup F\left(\varepsilon_{i_{2}}\right) \cup \cdots \cup F\left(\varepsilon_{i_{n}}\right)$. Furthermore, because $F\left(\varepsilon_{i_{1}}\right) \subset F(b), F\left(\varepsilon_{j_{1}}\right), F\left(\varepsilon_{j_{2}}\right), \ldots, F\left(\varepsilon_{j_{m}}\right)$ cannot be equal to $F(b)$, so $F\left(\varepsilon_{j_{1}}\right), F\left(\varepsilon_{j_{2}}\right), \ldots, F\left(\varepsilon_{j_{m}}\right), F\left(\varepsilon_{i_{i}}\right)$, $\ldots, F\left(\varepsilon_{i_{n}}\right)$ are not equal to either $F(a)$ or $F(b)$. That is, $\left\{F\left(\varepsilon_{j_{1}}\right), F\left(\varepsilon_{j_{2}}\right), \ldots, F\left(\varepsilon_{j_{m}}\right), F\left(\varepsilon_{i_{2}}\right), \ldots, F\left(\varepsilon_{i_{n}}\right)\right\} \subseteq\{F(\varepsilon) \mid \varepsilon \epsilon$ $A-\{a\}\}-\{F(b)\}$. Thus, $b$ is a reducible element of $A-\{a\}$. 
" $\Leftarrow$ " If $b$ is a reducible element of $A-\{a\}$, then $F(b)$ can be expressed as a union of some fuzzy sets in $\{F(\varepsilon) \mid \varepsilon \in A-$ $\{a\}\}-\{F(b)\}=\{F(\varepsilon) \mid \varepsilon \in A-\{a, b\}\}$. Obviously, $F(b)$ can be expressed as a union of some fuzzy sets in $\{F(\varepsilon) \mid \varepsilon \in A-\{b\}\}$, so $b$ is a reducible element of $A$.

Theorem 15 shows that deleting a reducible element in a set of parameters will not generate any new reducible elements or make other originally reducible elements become irreducible elements of the new set of parameters. So, we can compute the reduct of a set of parameters by deleting all reducible elements in the same time, or by deleting one reducible element in a step. The remaining set of parameters is irreducible. Especially, for a full fuzzy soft set, Theorem 14 guarantees that after deleting a reducible element in a set of parameters, the new fuzzy soft set is still a full fuzzy soft set.

Definition 16. For a fuzzy soft set $(F, A)$ over $U$, when we delete all reducible elements from $A$, the remaining irreducible set of parameters is called the reduct of $A$ and is denoted by $\operatorname{reduct}(A)$.

Theorem 15 guarantees that a set of parameters has only one reduct. An algorithm to compute the reduct of a set of parameters is shown as follows.

Example 17. In Example 9, $\operatorname{reduct}(A)=\operatorname{reduct}(B)=\operatorname{reduct}(C)$ $=\operatorname{reduct}(D)=D$

Definition 18. For a fuzzy soft set $(F, A)$ over $U$, the fuzzy soft set $\{F(\varepsilon) \mid \varepsilon \in \operatorname{reduct}(A)\}$ is called the reduct of $(F, A)$ and is denoted by $\operatorname{reduct}((F, A))$.

Theorem 19. If $(F, A)$ is a fuzzy soft set over $U$, a is a reducible element of $A$, and $\mu \in \mathscr{F}(U)$; then the lower soft fuzzy rough approximations $\operatorname{Apr}^{\prime}(\mu)$ of $\mu$ generated by the fuzzy soft set $(F, A)$ and the fuzzy soft set $\{F(\varepsilon) \mid \varepsilon \in A-\{a\}\}$, respectively, are the same.

Proof. Since $a$ is a reducible element of $A, F(a)$ can be expressed as a union of some fuzzy subsets in $\{F(\varepsilon) \mid \varepsilon \in$ $A-\{a\}\}$, say $F\left(\varepsilon_{1}\right), F\left(\varepsilon_{2}\right), \ldots, F\left(\varepsilon_{n}\right)$. Then, for any $x \in U$, we have

$$
\begin{aligned}
F(a)(x) \wedge\left(\bigwedge_{y \in U}((1-F(a)(y)) \vee \mu(y))\right) \\
=\left(\bigcup_{k=1}^{n} F\left(\varepsilon_{n}\right)\right)(x) \\
\wedge\left(\bigwedge_{y \in U}\left(\left(1-\left(\bigcup_{k=1}^{n} F\left(\varepsilon_{n}\right)\right)(y)\right) \vee \mu(y)\right)\right) \\
=\left(\bigvee_{k=1}^{n} F\left(\varepsilon_{k}\right)(x)\right) \\
\wedge\left(\bigwedge_{y \in U}\left(\left(1-\left(\bigvee_{k=1}^{n} F\left(\varepsilon_{k}\right)(y)\right)\right) \vee \mu(y)\right)\right)
\end{aligned}
$$

$$
\begin{aligned}
&=\left(\bigvee_{k=1}^{n} F\left(\varepsilon_{k}\right)(x)\right) \\
&\left.\wedge\left(\bigwedge_{y \in U}\left(\bigwedge_{k=1}^{n}\left(1-F\left(\varepsilon_{k}\right)(y)\right)\right) \vee \mu(y)\right)\right) \\
&=\left.\bigvee_{k=1}^{n} F\left(\varepsilon_{k}\right)(x)\right) \\
& \wedge\left(\bigwedge_{y \in U}^{n}\left(\bigwedge_{k=1}^{n}\left(\left(1-F\left(\varepsilon_{k}\right)(y)\right) \vee \mu(y)\right)\right)\right) \\
&=\left.\wedge\left(\bigwedge_{k=1}^{n} F\left(\varepsilon_{k}\right)(x)\right)\left(\left(1-F\left(\varepsilon_{k}\right)(y)\right) \vee \mu(y)\right)\right) \\
& \leq \bigvee_{k=1}^{n}\left(F\left(\varepsilon_{k}\right)(x) \wedge\left(\bigwedge_{y \in U}\left(\left(1-F\left(\varepsilon_{k}\right)(y)\right) \vee \mu(y)\right)\right)\right)
\end{aligned}
$$

Consequently, we have

$$
\begin{aligned}
\operatorname{Apr}_{(F, A)}^{\prime}(\mu)(x) & \\
= & \bigvee_{\varepsilon \in A}\left(F(\varepsilon)(x) \wedge\left(\bigwedge_{y \in U}((1-F(\varepsilon)(y)) \vee \mu(y))\right)\right) \\
= & \left(F(a)(x) \wedge\left(\bigwedge_{y \in U}((1-F(a)(y)) \vee \mu(y))\right)\right) \\
& \vee\left(\bigvee_{\varepsilon \in A-\{a\}}(F(\varepsilon)(x)\right. \\
= & \left.\bigvee_{\varepsilon \in A-\{a\}}\left(F\left(\bigwedge_{y \in U}((1-F(\varepsilon)(y)) \vee \mu(y))\right)\right)\right) \\
= & \underbrace{}_{\{F(\varepsilon) \mid \varepsilon \in A-\{a\}\}}(\mu) \wedge\left(\bigwedge_{y \in U}^{\prime}((1-F(\varepsilon)(y)) \vee \mu(y))\right)
\end{aligned}
$$

This theorem is proved.

Corollary 20. Suppose $(F, A)$ is a fuzzy soft set over $U$ and $\mu \in \mathscr{F}(U)$; then the lower soft fuzzy rough approximations $\operatorname{Apr}_{\mathfrak{S}}^{\prime}(\mu)$ of $\mu$ generated by the fuzzy soft sets $(F, A)$ and reduct $((F, A))$, respectively, are the same.

Proof. It directly follows from Definition 18 and Theorem 19. 
Theorem 21. If $(F, A)$ is a fuzzy soft set over $U$, a is a reducible element of $A$, and $\mu \in \mathscr{F}(U)$, then the upper soft fuzzy rough approximations $\overline{\operatorname{Apr}}_{\mathfrak{s}}^{\prime}(\mu)$ of $\mu$ generated by the fuzzy soft set $(F, A)$ and the fuzzy soft set $\{F(\varepsilon) \mid \varepsilon \in A-\{a\}\}$, respectively, are the same.

Proof. The proof is analogous to the proof of Theorem 19.

Corollary 22. Suppose $(F, A)$ is a fuzzy soft set over $U$ and $\mu \in \mathscr{F}(U)$; then the upper soft fuzzy rough approximations $\overline{\operatorname{Apr}}_{\Im}^{\prime}(\mu)$ of $\mu$ generated by the fuzzy soft sets $(F, A)$ and reduct $((F, A))$, respectively, are the same.

Proof. It directly follows from Definition 18 and Theorem 21.

Combining Corollaries 20 and 22, we have the following conclusions.

Theorem 23. Let $(F, A)$ be a fuzzy soft set over $U$; then $(F, A)$ and reduct $(F, A)$ ) generate the same lower soft fuzzy rough approximation operators $\mathrm{Apr}_{\mathfrak{s}}^{\prime}$ and the same upper soft fuzzy rough approximation operators $\overline{\mathrm{Apr}}_{\mathfrak{S}}^{\prime}$.

Theorem 24 (condition under which two different fuzzy soft sets generate the same $\operatorname{Apr}_{\mathfrak{S}}^{\prime}$ and $\left.\overline{\operatorname{Apr}}_{\mathfrak{S}}^{\prime}\right)$. Let $(F, A)$ and $(G, B)$ be two fuzzy soft sets over the same universe $U$. If $(F, A)$ and $(G, B)$ satisfy the condition in Proposition 11 and $\operatorname{reduct}((F, A))=\operatorname{reduct}((G, B))$, then $(F, A)$ and $(G, B)$ generate the same lower soft fuzzy rough approximation operators $\mathrm{Apr}_{\subseteq}^{\prime}$ and the same upper soft fuzzy rough approximation operators $\overline{\mathrm{Apr}}_{\mathfrak{S}}^{\prime}$.

Remark 25. When $A$ contains a large amount of parameters, calculating $\underline{\operatorname{Apr}}_{(F, A)}^{\prime}$ and $\overline{\operatorname{Apr}}_{(F, A)}^{\prime}$ using Definition 8 becomes very complex. Based on the above discussions, we may first calculate $\operatorname{reduct}(A)$ using Algorithm 1 and then calculate $\underline{\operatorname{Apr}}_{(F, A)}^{\prime}$ and $\overline{\operatorname{Apr}}_{(F, A)}^{\prime}$ using the following equations:

$$
\forall \mu \in \mathscr{F}(U), \quad x \in U
$$

$$
\begin{aligned}
& \operatorname{Apr}_{(F, A)}^{\prime}(\mu)(x) \\
& =\bigvee_{\varepsilon \in \operatorname{reduct}(A)}\left(F(\varepsilon)(x) \wedge\left(\bigwedge_{y \in U}((1-F(\varepsilon)(y)) \vee \mu(y))\right)\right), \\
& \overline{\operatorname{Apr}}_{(F, A)}^{\prime}(\mu)(x) \\
& =\bigwedge_{\varepsilon \in \operatorname{reduct}(A)}\left((1-F(\varepsilon)(x)) \vee\left(\bigvee_{y \in U}(F(\varepsilon)(y) \wedge \mu(y))\right)\right) .
\end{aligned}
$$

Example 26. Let $(F, A)$ be a fuzzy soft set over $U$ shown in Table 2. Let $\mu=\left\{\left\langle h_{1}, 0.3\right\rangle,\left\langle h_{2}, 0.5\right\rangle,\left\langle h_{3}, 0.1\right\rangle,\left\langle h_{4}, 0.7\right\rangle\right.$,



Algorithm 1

$\left.\left\langle h_{5}, 0.6\right\rangle,\left\langle h_{6}, 0.8\right\rangle\right\}$ be a fuzzy set on $U$. By Remark 25 and Example 17, we have

$$
\begin{aligned}
& \underline{\operatorname{Apr}}_{(F, A)}^{\prime}(\mu)\left(x_{1}\right) \\
& =\bigvee_{\varepsilon \in \operatorname{reduct}(A)}\left(F(\varepsilon)\left(x_{1}\right)\right. \\
& \left.\wedge\left(\bigwedge_{y \in U}((1-F(\varepsilon)(y)) \vee \mu(y))\right)\right) \\
& =0.4 \vee 0.1 \vee 0.5=0.5 \text {, } \\
& \underline{\operatorname{Apr}}_{(F, A)}^{\prime}(\mu)\left(x_{2}\right)=0.4 \vee 0.4 \vee 0.1=0.4 \text {, } \\
& \underline{\operatorname{Apr}}_{(F, A)}^{\prime}(\mu)\left(x_{3}\right)=0.2 \vee 0.4 \vee 0.3=0.4 \text {, } \\
& \underline{\operatorname{Apr}}_{(F, A)}^{\prime}(\mu)\left(x_{4}\right)=0.1 \vee 0.6 \vee 0.5=0.6 \text {, } \\
& \underline{\operatorname{Apr}}_{(F, A)}^{\prime}(\mu)\left(x_{5}\right)=0.4 \vee 0.1 \vee 0.3=0.4 \text {, } \\
& \underline{\operatorname{Apr}}_{(F, A)}^{\prime}(\mu)\left(x_{6}\right)=0.4 \vee 0.6 \vee 0.5=0.6 .
\end{aligned}
$$

Thus, $\underline{\operatorname{Apr}}_{(F, A)}^{\prime}(\mu)=\left\{\left\langle x_{1}, 0.5\right\rangle,\left\langle x_{2}, 0.4\right\rangle,\left\langle x_{3}, 0.4\right\rangle,\left\langle x_{4}, 0.6\right\rangle\right.$, $\left.\left.\left\langle x_{5}, 0.4\right\rangle, \overline{\left\langle x_{6}\right.}, 0.6\right\rangle\right\}$.

Similarly, we have $\overline{\operatorname{Apr}}_{(F, A)}^{\prime}(\mu)=\left\{\left\langle x_{1}, 0.6\right\rangle,\left\langle x_{2}, 0.6\right\rangle\right.$, $\left.\left\langle x_{3}, 0.7\right\rangle,\left\langle x_{4}, 0.7\right\rangle,\left\langle x_{5}, 0.6\right\rangle,\left\langle x_{6}, 0.6\right\rangle\right\}$.

\section{Exclusions of the Lower Soft Fuzzy Rough Approximation Operator $\mathrm{Apr}_{\Im}$ and Upper Soft Fuzzy Rough Approximation Operator $\overline{\mathrm{Apr}}_{\Im}$}

In the present section, we investigate similar issues to those in Section 3 for the the lower soft fuzzy rough approximation 
operator Apr ${ }_{\subseteq}$ and the upper soft fuzzy rough approximation operator $\overline{\overline{\mathrm{Apr}}}_{\mathbb{S}}$. It should be noted that the concept of reduct is not a very useful tool for the lower soft fuzzy rough approximation operator Apr $_{\subseteq}$ and upper soft fuzzy rough approximation operator $\overline{\overline{\mathrm{Apr}}}_{\Im}$. An illustrative example is as follows.

Example 27. $((F, A)$ and $\operatorname{reduct}((F, A))$ do not generate the same lower soft fuzzy rough approximation operator $\underline{A p r}_{\mathbb{S}}$ and the same upper soft fuzzy rough approximation operator $\left.\overline{\operatorname{Apr}}_{\widetilde{\varsigma}}\right)$. Let $(H, C)$ be a fuzzy soft set over $U$ shown in Table 4 . Let $(J, D)$ be a fuzzy soft set over $U$ shown in Table 5 . Let $\mu=$ $\left\{\left\langle h_{1}, 0.3\right\rangle,\left\langle h_{2}, 0.5\right\rangle,\left\langle h_{3}, 0.1\right\rangle,\left\langle h_{4}, 0.7\right\rangle,\left\langle h_{5}, 0.6\right\rangle,\left\langle h_{6}, 0.8\right\rangle\right\}$ be a fuzzy set on $U$. By Example 17, we know that reduct $((H, C))=(J, D)$. According to Definition 7, we have

$$
\begin{aligned}
& \underline{\operatorname{Apr}}_{(J, D)}(\mu)\left(x_{4}\right) \\
& =\bigwedge_{\varepsilon \in D}\left(\left(1-F(\varepsilon)\left(x_{4}\right)\right)\right. \\
& \left.\vee\left(\bigwedge_{y \in U}((1-F(\varepsilon)(y)) \vee \mu(y))\right)\right) \\
& =0.5 \text {, } \\
& \overline{\operatorname{Apr}}_{(J, D)}(\mu)\left(x_{2}\right) \\
& =\bigvee_{\varepsilon \in D}\left(F(\varepsilon)\left(x_{2}\right) \wedge\left(\bigvee_{y \in U}(F(\varepsilon)(y) \wedge \mu(y))\right)\right)=0.6 \text {, } \\
& \underline{\operatorname{Apr}}_{(H, C)}(\mu)\left(x_{4}\right) \\
& =\bigwedge_{\varepsilon \in C}\left(\left(1-F(\varepsilon)\left(x_{4}\right)\right)\right. \\
& \left.\vee\left(\bigwedge_{y \in U}((1-F(\varepsilon)(y)) \vee \mu(y))\right)\right) \\
& =0.4 \text {, } \\
& \overline{\operatorname{Apr}}_{(H, C)}(\mu)\left(x_{2}\right) \\
& =\bigvee_{\varepsilon \in C}\left(F(\varepsilon)\left(x_{2}\right) \wedge\left(\bigvee_{y \in U}(F(\varepsilon)(y) \wedge \mu(y))\right)\right)=0.7
\end{aligned}
$$

Therefore, $(H, C)$ and $(J, D)$ do not generate the same lower soft fuzzy rough approximation operator $\mathrm{Apr}_{\varsigma}$ and the same upper soft fuzzy rough approximation operator $\overline{\mathrm{Apr}}_{\mathfrak{\subseteq}}$.

Example 28 (two different fuzzy soft sets generate the same lower soft fuzzy rough approximation operator $\mathrm{Apr}_{\widetilde{\Phi}}$ and the same upper soft fuzzy rough approximation operator $\overline{\mathrm{Apr}}_{\Im}$ ).
TABLE 6: Tabular representation of $(M, N)$.

\begin{tabular}{lcc}
\hline$U$ & $\varepsilon_{1}$ & $\varepsilon_{5}$ \\
\hline$x_{1}$ & 0.6 & 0.5 \\
$x_{2}$ & 0.8 & 0.1 \\
$x_{3}$ & 0.4 & 0.3 \\
$x_{4}$ & 0.6 & 0.5 \\
$x_{5}$ & 0.5 & 0.3 \\
$x_{6}$ & 0.7 & 0.9 \\
\hline
\end{tabular}

Let $(H, C)$ be a fuzzy soft set over $U$ shown in Table 4 . Let $(M, N)$ be a fuzzy soft set over $U$ shown in Table 6 , where $N=\left\{\varepsilon_{1}, \varepsilon_{5}\right\}$.

By Definition 7, we know that $(H, C)$ and $(M, N)$ generate the same lower soft fuzzy rough approximation operator $\underline{A p r}_{\subseteq}$ and the same upper soft fuzzy rough approximation operator $\overline{\operatorname{Apr}}_{\mathfrak{S}}$. Thus, we need to examine the conditions under which two different fuzzy soft sets generate the same lower soft fuzzy rough approximation operator $\underline{A p r}_{\mathbb{S}}$ and the same upper soft fuzzy rough approximation operator $\overline{\mathrm{Apr}}_{\mathfrak{S}}$. To address this issue, we introduce the following novel concept called exclusions.

Definition 29. Let $(F, A)$ be a fuzzy soft set over $U$ and $a \in A$. If there exists another parameter $b \in A$ such that $F(a) \subset F(b)$, then we say that $a$ is an immured element of $A$.

Proposition 30. Let $(F, A)$ be a fuzzy soft set over $U$. Then $\varepsilon$ is an immured element of $A$ if and only if there exists a parameter $\eta \in A-\{\varepsilon\}$ such that $F(\varepsilon)(x) \leq F(\eta)(x)$ for any $x \in U$.

Proof. According to Definition 29, we have the following:

$\varepsilon$ is an immured element of $A$,

$\Leftrightarrow$ there exists another parameter $\eta \in A-\{\varepsilon\}$ such that $F(\varepsilon) \subset F(\eta)$,

$\Leftrightarrow F(\varepsilon)(x) \leq F(\eta)(x), \forall x \in U$.

Example 31. For the fuzzy soft set $(H, C)$ in Table $4, \varepsilon_{2}$ is an immured element of $C$.

Definition 32. Let $(F, A)$ be a fuzzy soft set over $U$. If every parameter of $A$ is not an immured element, we call $A$ semireduced or semi-irredundant.

Theorem 33. Let $(F, A)$ be a full fuzzy soft set over $U$. If $a$ is an immured element of $A$, then $\{F(\varepsilon) \mid \varepsilon \in A-\{a\}\}$ is still a full fuzzy soft set over $U$.

Proof. It follows from Definitions 4 and 29.

Theorem 34. Let $(F, A)$ be a fuzzy soft set over $U, a \in A, a$ an immured element of $A$, and $b \in A-\{a\}$; then, $b$ is an immured element of $A$ if and only if it is an immured element of $A-\{a\}$. 
Proof. " $\Rightarrow$ " If $b$ is an immured element of $A$, then there exists $c \in A-\{b\}$ such that $F(b) \subset F(c)$. Since $a$ is an immured element of $A$, there exists $d \in A-\{a\}$ such that $F(a) \subset F(d)$. If $c=a$, then $F(b) \subset F(c)=F(a) \subset F(d)$. If $c \neq a$, then $c \in(A-\{a\})-\{b\}=A-\{a, b\}$. Therefore, $b$ is an immured element of $A-\{a\}$.

" $\Leftarrow$ " If $b$ is an immured element of $A-\{a\}$, then there exists $c \in A-\{a, b\}$ such that $F(b) \subset F(c)$. Clearly, $b$ is also an immured element of $A$.

Theorem 34 shows that deleting an immured element in a set of parameters will not generate any new reducible elements or make other originally immured elements become no immured elements of the new set of parameters. So, we can compute the exclusion of a set of parameters by deleting all immured elements in the same time, or by deleting one immured element in a step. The remaining set of parameters is not immured. In particular, for a full fuzzy soft set, Theorem 33 guarantees that after deleting an immured element in a set of parameters, the new fuzzy soft set is still a full fuzzy soft set.

Definition 35. Let $(F, A)$ be a fuzzy soft set over $U$. When we remove all the immured parameters from $A$, the set of all remaining parameters is called an exclusion of $A$ and is denoted by exclusion $(A)$.

Theorem 34 guarantees that a set of parameters has only one exclusion. We give an algorithm to compute the exclusion of a set of parameters as follows.

Example 36. In Example 28, $\operatorname{exclusion}(C)=\operatorname{exclusion}(N)=$ N.

Definition 37. For a fuzzy soft set $(F, A)$ over $U$, the fuzzy soft set $\{F(\varepsilon) \mid \varepsilon \in \operatorname{exclusion}(A)\}$ is called the exclusion of $(F, A)$ and is denoted by exclusion $((F, A))$.

Theorem 38. If $(F, A)$ is a fuzzy soft set over $U$, $a$ is an immured element of $A$, and $\mu \in \mathscr{F}(U)$, then the lower soft fuzzy rough approximations $\operatorname{Apr}_{\mathfrak{S}}(\mu)$ of $\mu$ generated by the fuzzy soft $\operatorname{set}(F, A)$ and the fuzzy soft set $\{F(\varepsilon) \mid \varepsilon \in A-\{a\}\}$, respectively, are the same.

Proof. Since $a$ is an immured element of $A$, there exists another element $b \in A-\{a\}$ such that $F(a) \subset F(b)$. For any $x \in U$, we have

$$
\begin{aligned}
(1-F(a)(x)) \vee\left(\bigwedge_{y \in U}((1-F(a)(y)) \vee \mu(y))\right) \\
\geq(1-F(a)(x)) \vee\left(\bigwedge_{y \in U}((1-F(b)(y)) \vee \mu(y))\right) \\
\geq(1-F(b)(x)) \vee\left(\bigwedge_{y \in U}((1-F(b)(y)) \vee \mu(y))\right) .
\end{aligned}
$$

Thus, we have

$$
\begin{aligned}
& \underline{\operatorname{Apr}}_{(F, A)}(\mu)(x) \\
& =\bigwedge_{\varepsilon \in A}((1-F(\varepsilon)(x)) \\
& \left.\vee\left(\bigwedge_{y \in U}((1-F(\varepsilon)(y)) \vee \mu(y))\right)\right) \\
& =\left((1-F(a)(x)) \vee\left(\bigwedge_{y \in U}((1-F(a)(y)) \vee \mu(y))\right)\right) \\
& \wedge\left(\bigwedge_{\varepsilon \in A-\{a\}}((1-F(\varepsilon)(x))\right. \\
& \left.\left.\vee\left(\bigwedge_{y \in U}((1-F(\varepsilon)(y)) \vee \mu(y))\right)\right)\right) \\
& =\bigwedge_{\varepsilon \in A-\{a\}}((1-F(\varepsilon)(x)) \\
& \left.\vee\left(\bigwedge_{y \in U}((1-F(\varepsilon)(y)) \vee \mu(y))\right)\right) \\
& =\underline{\operatorname{Apr}}_{\{F(\varepsilon) \mid \varepsilon \in A-\{a\}\}}(\mu)(x) .
\end{aligned}
$$

This theorem is proved.

Corollary 39. Suppose $(F, A)$ is a fuzzy soft set over $U$ and $\mu \in \mathscr{F}(U)$; then the lower soft fuzzy rough approximations $\operatorname{Apr}_{\mathfrak{s}}(\mu)$ of $\mu$ generated by the fuzzy soft sets $(F, A)$ and exclusion $((F, A))$, respectively, are the same.

Proof. It follows from Definition 37 and Theorem 38.

Theorem 40. If $(F, A)$ is a fuzzy soft set over $U, a$ is an immured element of $A$, and $\mu \in \mathscr{F}(U)$, then the upper soft fuzzy rough approximations $\overline{\operatorname{Apr}}_{\mathbb{S}}(\mu)$ of $\mu$ generated by the fuzzy soft set $(F, A)$ and the fuzzy soft set $\{F(\varepsilon) \mid \varepsilon \in A-\{a\}\}$, respectively, are the same.

Proof. Since $a$ is an immured element of $A$, there exists another element $b \in A-\{a\}$ such that $F(a) \subset F(b)$. For any $x \in U$, we have

$$
\begin{aligned}
& F(a)(x) \wedge\left(\bigvee_{y \in U}(F(a)(y) \wedge \mu(y))\right) \\
& \leq F(a)(x) \wedge\left(\bigvee_{y \in U}(F(b)(y) \wedge \mu(y))\right) \\
& \leq F(b)(x) \wedge\left(\bigvee_{y \in U}(F(b)(y) \wedge \mu(y))\right) .
\end{aligned}
$$


Consequently, we have

$$
\begin{aligned}
\overline{\operatorname{Apr}}_{(F, A)}(\mu)(x) & \bigvee_{\varepsilon \in A}\left(F(\varepsilon)(x) \wedge\left(\bigvee_{y \in U}(F(\varepsilon)(y) \wedge \mu(y))\right)\right) \\
= & \left(F(a)(x) \wedge\left(\bigvee_{y \in U}(F(a)(y) \wedge \mu(y))\right)\right) \\
& \vee\left(\bigvee_{\varepsilon \in A-\{a\}}(F(\varepsilon)(x)\right. \\
= & \bigvee_{\varepsilon \in A-\{a\}}\left(F(\varepsilon)(x) \wedge\left(\bigvee_{y \in U}(F(\varepsilon)(y) \wedge \mu(y))\right)\right) \\
= & \overline{\operatorname{Apr}}_{\{F(\varepsilon) \mid \varepsilon \in A-\{a\}\}}(\mu)(x) .
\end{aligned}
$$

This theorem is proved.

Corollary 41. Suppose $(F, A)$ is a fuzzy soft set over $U$ and $\mu \in \mathscr{F}(U)$; then the upper soft fuzzy rough approximations $\overline{\operatorname{Apr}}_{\mathbb{S}}(\mu)$ of $\mu$ generated by the fuzzy soft sets $(F, A)$ and exclusion $((F, A))$, respectively, are the same.

Proof. It follows from Definition 37 and Theorem 40.

Combining Corollaries 39 and 41, we have the following conclusions.

Theorem 42. Let $(F, A)$ be a fuzzy soft set over $U$; then $(F, A)$ and exclusion $(F, A))$ generate the same lower soft fuzzy rough approximation operators $\mathrm{Apr}_{\mathbb{S}}$ and the same upper soft fuzzy rough approximation operators $\overline{\mathrm{Apr}}_{\mathfrak{S}}$.

Theorem 43 (condition under which two different fuzzy soft sets generate the same $\operatorname{Apr}_{\mathfrak{S}}$ and $\left.\overline{\operatorname{Apr}}_{\mathfrak{S}}\right)$. Let $(F, A)$ and $(G, B)$ be two fuzzy soft sets over the same universe $U$. If $(F, A)$ and $(G, B)$ satisfy the condition in Proposition 30 and $\operatorname{exclusion}((F, A))=\operatorname{exclusion}((G, B))$, then $(F, A)$ and $(G, B)$ generate the same lower soft fuzzy rough approximation operators $\mathrm{Apr}_{\mathfrak{S}}$ and the same upper soft fuzzy rough approximation operators $\overline{\mathrm{Apr}}_{\mathfrak{S}}$.

Remark 44. When $A$ contains a large amount of parameters, calculating $\underline{\mathrm{Apr}}_{(F, A)}$ and $\overline{\operatorname{Apr}}_{(F, A)}$ using Definition 7 becomes very complex. Based on the above discussions, we may first calculate exclusion $(A)$ using Algorithm 2 and then calculate $\underline{\operatorname{Apr}}_{(F, A)}$ and $\overline{\operatorname{Apr}}_{(F, A)}$ using the following equations:

$$
\forall \mu \in \mathscr{F}(U), \quad x \in U,
$$

set exclusion $(A)=A$;

for $(i=1 ; i \leq n ; i++)$

ffor $(j=1 ; j \leq n ; j++)$

$\left\{\operatorname{iff}\left(F\left(\varepsilon_{i}\right) \subset F\left(\varepsilon_{j}\right)\right)\right.$ $\left\{\operatorname{exclusion}(A)=\operatorname{exclusion}(A)-\left\{\varepsilon_{i}\right\}\right.$; break; \}

Algorithm 2

$$
\begin{aligned}
& \underline{\operatorname{Apr}}_{(F, A)}(\mu)(x) \\
& =\bigwedge_{\varepsilon \in \operatorname{exclusion}(A)}((1-F(\varepsilon)(x)) \\
& \left.\vee\left(\bigwedge_{y \in U}((1-F(\varepsilon)(y)) \vee \mu(y))\right)\right), \\
& \overline{\operatorname{Apr}}_{(F, A)}(\mu)(x) \\
& =\bigvee_{\varepsilon \in \operatorname{exclusion}(A)}(F(\varepsilon)(x) \\
& \left.\wedge\left(\bigvee_{y \in U}(F(\varepsilon)(y) \wedge \mu(y))\right)\right) .
\end{aligned}
$$

Example 45. Let $(H, C)$ be a fuzzy soft set over $U$ shown in Table 4 . Let $\mu=\left\{\left\langle h_{1}, 0.3\right\rangle,\left\langle h_{2}, 0.5\right\rangle,\left\langle h_{3}, 0.1\right\rangle\right.$, $\left.\left\langle h_{4}, 0.7\right\rangle,\left\langle h_{5}, 0.6\right\rangle,\left\langle h_{6}, 0.8\right\rangle\right\}$ be a fuzzy set on $U$. By Remark 44 and Example 36, we have

$$
\begin{aligned}
& \operatorname{Apr}_{(H, C)}(\mu)\left(x_{1}\right) \\
& =\bigwedge_{\varepsilon \in \text { exclusion }(C)}\left(\left(1-F(\varepsilon)\left(x_{1}\right)\right)\right. \\
& \left.\vee\left(\bigwedge_{y \in U}((1-F(\varepsilon)(y)) \vee \mu(y))\right)\right) \\
& =0.4 \wedge 0.5=0.4 \text {, } \\
& \underline{\operatorname{Apr}}_{(H, C)}(\mu)\left(x_{2}\right)=0.4 \wedge 0.9=0.4, \\
& \underline{\operatorname{Apr}}_{(H, C)}(\mu)\left(x_{3}\right)=0.6 \wedge 0.7=0.6, \\
& \underline{\operatorname{Apr}}_{(H, C)}(\mu)\left(x_{4}\right)=0.4 \wedge 0.5=0.4, \\
& \underline{\operatorname{Apr}}_{(H, C)}(\mu)\left(x_{5}\right)=0.5 \wedge 0.7=0.5, \\
& \underline{\operatorname{Apr}}_{(H, C)}(\mu)\left(x_{6}\right)=0.4 \wedge 0.5=0.4 \text {. }
\end{aligned}
$$


Thus, $\operatorname{Apr}_{(H, C)}(\mu)=\left\{\left\langle x_{1}, 0.4\right\rangle,\left\langle x_{2}, 0.4\right\rangle,\left\langle x_{3}, 0.6\right\rangle,\left\langle x_{4}, 0.4\right\rangle\right.$, $\left.\left\langle x_{5}, 0.5\right\rangle,\left\langle x_{6}, 0.4\right\rangle\right\}$.

Similarly, we have $\overline{\operatorname{Apr}}_{(H, C)}(\mu)=\left\{\left\langle x_{1}, 0.6\right\rangle,\left\langle x_{2}, 0.7\right\rangle\right.$, $\left.\left\langle x_{3}, 0.4\right\rangle,\left\langle x_{4}, 0.6\right\rangle,\left\langle x_{5}, 0.5\right\rangle,\left\langle x_{6}, 0.8\right\rangle\right\}$.

\section{Conclusions}

In this paper, we recall the notion of soft fuzzy rough sets as a combination of soft sets, fuzzy sets, and rough sets. Then, by employing two concepts of reduct and exclusion, we give some conditions for two different fuzzy soft sets to generate an identical lower soft fuzzy rough approximation operator and an identical upper soft fuzzy rough approximation operator. In future research, it is desirable to address the axiomatization issue of the lower and upper soft fuzzy rough approximation operators. In addition, topological properties of soft fuzzy rough approximation operators are also a potential topic for future research. On the other hand, the applications of soft fuzzy rough sets to practical fields are exciting areas to be explored. We will focus on these issues in our future works.

\section{Acknowledgments}

The author thanks the anonymous referees for their valuable suggestions in improving this paper. This work was supported by the National Natural Science Foundation of China (Grant no. 61073121) and the Natural Science Foundation of the Hebei Province of China (Grant nos. F2010000318, F2012201014, F2013201060, and A2012201033).

\section{References}

[1] D. Molodtsov, "Soft set theory-first results," Computers and Mathematics with Applications, vol. 37, no. 4-5, pp. 19-31, 1999.

[2] U. Acar, F. Koyuncu, and B. Tanay, "Soft sets and soft rings," Computers and Mathematics with Applications, vol. 59, no. 11, pp. 3458-3463, 2010.

[3] H. Aktaş and N. Çağman, "Soft sets and soft groups," Information Sciences, vol. 177, no. 13, pp. 2726-2735, 2007.

[4] M. I. Ali, "A note on soft sets, rough soft sets and fuzzy soft sets," Applied Soft Computing Journal, vol. 11, no. 4, pp. 3329-3332, 2011.

[5] M. I. Ali, F. Feng, X. Liu, W. K. Min, and M. Shabir, "On some new operations in soft set theory," Computers and Mathematics with Applications, vol. 57, no. 9, pp. 1547-1553, 2009.

[6] A. Aygünoglu and H. Aygün, "Introduction to fuzzy soft groups," Computers and Mathematics With Applications, vol. 58, pp. 1279-1286, 2009.

[7] D. Chen, E. C. C. Tsang, D. S. Yeung, and X. Wang, "The parameterization reduction of soft sets and its applications," Computers and Mathematics with Applications, vol. 49, no. 5-6, pp. 757-763, 2005.

[8] F. Feng, Y. B. Jun, and X. Zhao, "Soft semirings," Computers and Mathematics with Applications, vol. 56, no. 10, pp. 2621-2628, 2008.

[9] F. Feng, C. Li, B. Davvaz, and M. I. Ali, "Soft sets combined with fuzzy sets and rough sets: a tentative approach," Soft Computing, vol. 14, no. 9, pp. 899-911, 2010.
[10] F. Feng, X. Liu, V. Leoreanu-Fotea, and Y. B. Jun, "Soft sets and soft rough sets," Information Sciences, vol. 181, no. 6, pp. 11251137, 2011.

[11] Y. B. Jun, "Soft BCK/BCI-algebras," Computers and Mathematics with Applications, vol. 56, no. 5, pp. 1408-1413, 2008.

[12] Y. B. Jun and C. H. Park, "Applications of soft sets in ideal theory of BCK/BCI-algebras," Information Sciences, vol. 178, no. 11, pp. 2466-2475, 2008.

[13] Z. Kong, L. Gao, L. Wang, and S. Li, "The normal parameter reduction of soft sets and its algorithm," Computers and Mathematics with Applications, vol. 56, no. 12, pp. 3029-3037, 2008.

[14] X. Ma, N. Sulaiman, H. Qin, T. Herawan, and J. M. Zain, "A new efficient normal parameter reduction algorithm of soft sets," Computers and Mathematics with Applications, vol. 62, no. 2, pp. 588-598, 2011.

[15] P. K. Maji, R. Biswas, and A. R. Roy, "Soft set theory," Computers and Mathematics with Applications, vol. 45, no. 4-5, pp. 555-562, 2003.

[16] P. K. Maji, A. R. Roy, and R. Biswas, "An application of soft sets in a decision making problem," Computers and Mathematics with Applications, vol. 44, no. 8-9, pp. 1077-1083, 2002.

[17] W. K. Min, "Similarity in soft set theory," Applied Mathematics Letters, vol. 25, pp. 310-314, 2012.

[18] C. F. Yang, "Fuzzy soft semigroups and fuzzy soft ideals," Computers and Mathematics with Applications, vol. 61, no. 2, pp. 255-261, 2011.

[19] Y. Zou and Z. Xiao, "Data analysis approaches of soft sets under incomplete information," Knowledge-Based Systems, vol. 21, no. 8, pp. 941-945, 2008.

[20] P. K. Maji, R. Biswas, and A. R. Roy, “Fuzzy soft sets," Journal of Fuzzy Mathematics, vol. 9, no. 3, pp. 589-602, 2001.

[21] P. Majumdar and S. K. Samanta, "Generalised fuzzy soft sets," Computers and Mathematics with Applications, vol. 59, no. 4, pp. 1425-1432, 2010.

[22] X. Yang, T. Y. Lin, J. Yang, Y. Li, and D. Yu, "Combination of interval-valued fuzzy set and soft set," Computers and Mathematics with Applications, vol. 58, no. 3, pp. 521-527, 2009.

[23] W. Xu, J. Ma, S. Wang, and G. Hao, "Vague soft sets and their properties," Computers and Mathematics with Applications, vol. 59, no. 2, pp. 787-794, 2010.

[24] P. K. Maji, "More on intuitionistic fuzzy soft sets," Lecture Notes in Computer Science, vol. 5908, pp. 231-240, 2009.

[25] P. K. Maji, R. Biswas, and A. R. Roy, "Intuitionistic fuzzy soft sets," Journal of Fuzzy Mathematics, vol. 9, pp. 677-692, 2001.

[26] P. K. Maji, R. Biswas, and A. R. Roy, "On intuitionistic fuzzy soft sets," Journal of Fuzzy Mathematics, vol. 12, pp. 669-683, 2004.

[27] Y. Jiang, Y. Tang, Q. Chen, H. Liu, and J. Tang, "Interval-valued intuitionistic fuzzy soft sets and their properties," Computers and Mathematics with Applications, vol. 60, no. 3, pp. 906-918, 2010.

[28] F. Feng, Y. B. Jun, X. Liu, and L. Li, "An adjustable approach to fuzzy soft set based decision making," Journal of Computational and Applied Mathematics, vol. 234, no. 1, pp. 10-20, 2010.

[29] F. Feng, Y. Li, and V. Leoreanu-Fotea, "Application of level soft sets in decision making based on interval-valued fuzzy soft sets," Computers and Mathematics with Applications, vol. 60, no. 6, pp. 1756-1767, 2010.

[30] Y. Jiang, Y. Tang, and Q. Chen, "An adjustable approach to intuitionistic fuzzy soft sets based decision making," Applied Mathematical Modelling, vol. 35, no. 2, pp. 824-836, 2010. 
[31] Z. Kong, L. Gao, and L. Wang, "Comment on 'A fuzzy soft set theoretic approach to decision making problems"' Journal of Computational and Applied Mathematics, vol. 223, no. 2, pp. 540-542, 2009.

[32] A. R. Roy and P. K. Maji, "A fuzzy soft set theoretic approach to decision making problems," Journal of Computational and Applied Mathematics, vol. 203, no. 2, pp. 412-418, 2007.

[33] Z. Pawlak, "Rough sets," International Journal of Computer \& Information Sciences, vol. 11, no. 5, pp. 341-356, 1982.

[34] D. Meng, X. H. Zhang, and K. Y. Qin, "Soft rough fuzzy sets and soft fuzzy rough sets," Computers and Mathematics With Applications, vol. 62, no. 12, pp. 4635-4645, 2011.

[35] B. Z. Sun and W. M. Ma, "Soft fuzzy rough sets and its application in decision making," in Artificial Intelligence Review, Springer, Berlin, Germany, 2011.

[36] W. Zhu and F. Y. Wang, "On three types of covering-based rough sets," IEEE Transactions on Knowledge and Data Engineering, vol. 19, no. 8, pp. 1131-1144, 2007.

[37] D. Dubois and H. Prade, "Rough fuzzy sets and fuzzy rough sets," International Journal of General Systems, vol. 17, pp. 191209, 1990.

[38] L. A. Zadeh, "Fuzzy sets," Information and Control, vol. 8, no. 3, pp. 338-353, 1965. 



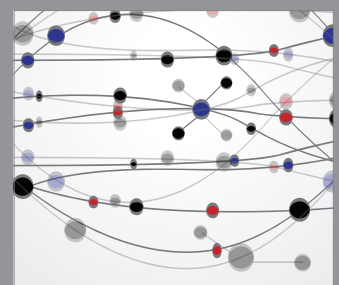

The Scientific World Journal
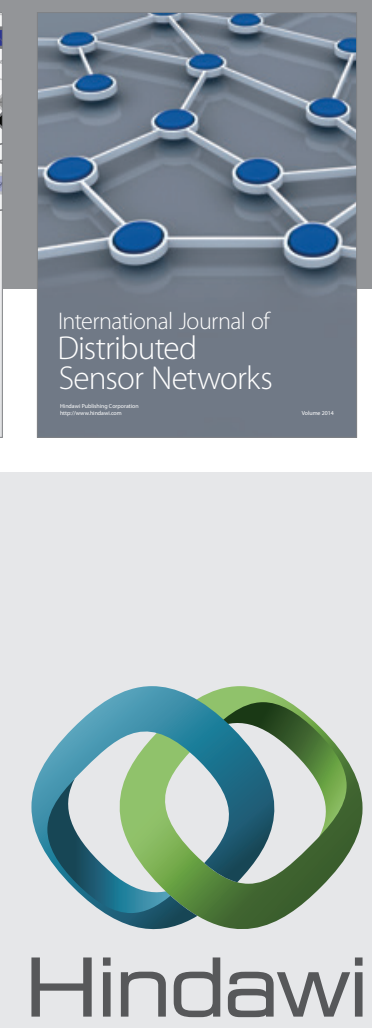

Submit your manuscripts at

http://www.hindawi.com
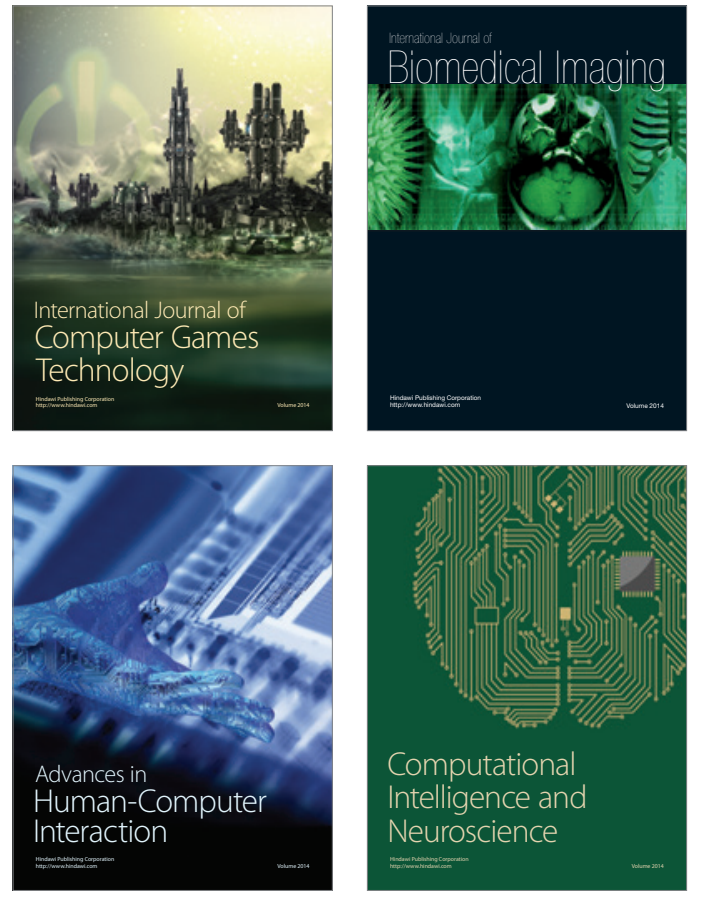
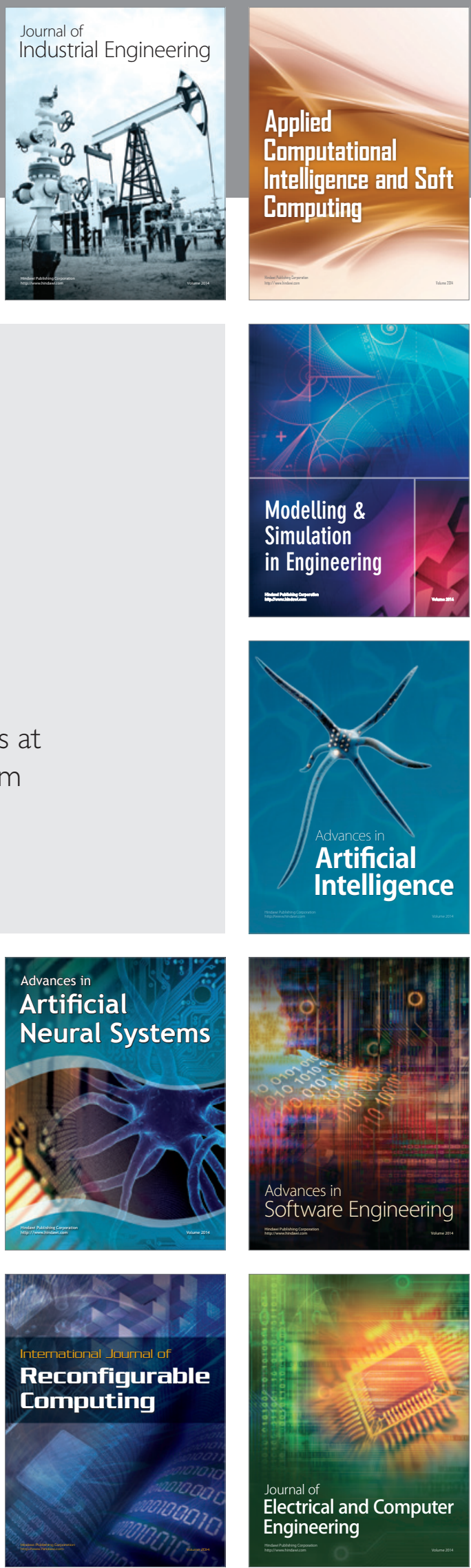